\title{
ANALISIS PENGGUNAAN ANTIBIOTIK PADA PASIEN ANAK DI RUANG THERESIA RUMAH SAKIT ST. ELISABETH SEMARANG DENGAN METODE ATC/DDD
}

\author{
Fef Rukminingsih $^{1}$, Apriliyani $^{2}$ \\ ${ }^{1,2}$ Politeknik Katolik Mangunwijaya \\ Email korespondensi: fefrukminingsih@gmail.com
}

\begin{abstract}
ABSTRAK
Kejadian penyakit infeksi yang tinggi menyebabkan penggunaan antibiotik meningkat. Penggunaan antibiotik yang tidak tepat akan menyebabkan terjadinya resistensi. Penyakit infeksi termasuk dalam 10 besar penyakit pada pasien anak di Rumah Sakit St. Elisabeth Semarang. Penelitian ini bertujuan untuk mengevaluasi penggunaan antibiotik pada pasien anak di ruang Theresia RS St. Elisabeth Semarang. Penelitian ini merupakan penelitian dekstriptif observasional dengan menggunakan data retrospektif. Pengambilan sampel menggunakan teknik purposive sampling. Data diambil dari data rekam medik pasien anak di ruang Theresia Rumah Sakit St. Elisabeth Semarang yang berusia 6 bulan - 14 tahun, penggunaan terapi antibiotik selama periode Oktober - Desember 2019. Data yang diperoleh dianalisis dengan menghitung kuantitas penggunaan antibiotik menggunakan metode Anatomical Therapeutic Chemical (ATC) dan Defined Daily Dose (DDD) )/100 patient-days. Berdasarkan hasil penelitian diketahui jumlah pasien anak di ruang Theresia Rumah Sakit St. Elisabeth Semarang periode Oktober - Desember 2019 adalah 385. Jumlah pasien yang mendapatkan antibiotik tunggal sebanyak 162. Nilai total DDD/100 patient-days di Ruang Theresia RS St. Elisabeth Semarang periode Oktober - Desember 2019 adalah 18,17 dengan total lama rawat inap 1117 hari. Antibiotik dengan nilai DDD/100 patient-days paling tinggi adalah seftriakson yaitu 15,10 . Sedangkan antibiotika yang masuk ke dalam segmen DU 90\% yaitu seftriakson dan sefotaksim.
\end{abstract}

Kata kunci : Antibiotik, ATC/DDD, DDD/100 patient-days, RS St. Elisabeth 


\title{
ANALYSIS OF THE USE OF ANTIBIOTICS IN CHILDREN PATIENTS IN THERESIA WARD ST. ELISABETH HOSPITAL SEMARANG USING ATC / DDD METHOD
}

\begin{abstract}
The high incidence of infectious diseases causes the use of antibiotics to increase. Inappropriate use of antibiotics will lead to resistance. Infectious diseases are included in the top 10 diseases in pediatric patients at St. Elisabeth Hospital.Semarang. This study aims to evaluate the use of antibiotics in pediatric patients in the Theresia ward of St. Elisabeth Hospital Semarang. This research is a descriptive observational study using retrospective data. Sampling using purposive sampling technique. Data were taken from medical records of pediatric patients in the Theresia ward at St. Elisabeth Hospital Semarang, aged 6 months - 14 years, the use of antibiotic therapy during the period October - December 2019. The data obtained were analyzed by calculating the quantity of antibiotic use using the Anatomical Therapeutic Chemical (ATC) and Defined Daily Dose (DDD)) / 100 patient-days methods. Based on the research results, it is known that the number of pediatric patients in the Theresia room at St. Elisabeth Semarang for the period October - December 2019 is 385. The number of patients who received a single antibiotic was 162. The total value of DDD / 100 patient-days in the Theresia ward of St. Elisabeth Hospital Semarang for the period October - December 2019 is 18.17 with a total length of stay of 1117 days. The antibiotic with the highest DDD / 100 patient-days was ceftriaxone, namely 15.10. While the antibiotics that enter the DU 90\% segment are ceftriaxone and cefotaxime.
\end{abstract}

Keywords : Antibiotic, ATC/DDD, DDD/100 patient-days, St. Elisabeth Hospital

\section{PENDAHULUAN}

Penyakit infeksi paling banyak menyerang pada anak-anak, dikarenakan sistem imun yang belum terbentuk sempurna (Carolina, 2014). Berdasarkan penelitian Sarimawar dan Ning (2014) diketahui bahwa kematian tertinggi pada bayi dan anak balita adalah akibat penyakit infeksi. Perlu adanya upaya dan penanganan yang tepat dalam pencegahan dan penyembuhan penyakit infeksi khususnya pada pasien anak. Penanganan untuk penyakit infeksi yang disebabkan oleh bakteri menggunakan antibiotik (Kemenkes RI, 2011).

Angka kejadian penyakit infeksi yang tinggi pada anak-anak menyebabkan kuantitas penggunaan antibiotik meningkat. Hasil penelitian yang dilakukan di ruang rawat Departemen Ilmu Kesehatan Anak RSUPN Cipto Mangunkusumo menyebutkan bahwa sebanyak 49,2\% pasien anak mendapatkan terapi antibiotik, yang terdiri dari 39,6\% mendapatkan antibiotik secara tepat dan 48,3\% mendapatkan antibiotik yang tidak tepat. Penggunaan antibiotik yang 
tidak tepat dapat memicu terjadinya resistensi (Satari el al., 2011). Resistensi antibiotik dapat menyebabkan peningkatan morbiditas, mortalitas dan biaya kesehatan, oleh sebab itu perlu adanya evaluasi penggunaan antibiotik (Kemenkes RI, 2011).

Evaluasi penggunaan antibiotik bertujuan untuk mengetahui jumlah penggunaan antibiotik, mengetahui dan mengevaluasi kualitas penggunaan antibiotik, serta sebagai indikator kualitas pelayanan. Evaluasi penggunaan antibiotik dapat dilakukan secara kuantitatif dan kualitatif. Evaluasi secara kualitatif dapat dilakukan dengan metode Gyssen, untuk mengevaluasi ketepatan penggunaan antibiotik. Evaluasi secara kuantitatif dilakukan untuk menghitung kuantitas penggunaan antibiotik menggunakan metode Defined Daily Dose yang disingkat DDD (Kemenkes RI, 2011).

Metode DDD merupakan metode evaluasi penggunaan obat yang dikembangkan oleh World Health Organization (WHO). WHO menetapkan metode spesifik dan terstandarisasi untuk klasifikasi penggunaan antibiotik yaitu Anatomical Therapeutic Chemical (ATC) dan pengukuran kuantitas antibiotika Defined Daily Dose (DDD)/100 patientdays. Data penggunaan obat dalam DDD memberikan perkiraan konsumsi dan bukan gambaran yang tepat tentang penggunaan obat yang sebenarnya. DDD merupakan unit pengukuran tetap yang memungkinkan untuk menilai tren penggunaan obat (WHO, 2019).
Penyakit infeksi termasuk dalam daftar 10 besar penyakit pada pasien anak di RS St. Elisabeth Semarang. Penelitian ini bertujuan untuk mengevaluasi penggunaan antibiotik secara kuantitatif pada pasien anak di ruang Theresia RS St. Elisabeth Semarang.

\section{METODE PENELITIAN}

Penelitian ini merupakan penelitian deskriptif observasional menggunakan data retrospektif. Pengambilan sampel menggunakan teknik purposive sampling. Data diperoleh dari data rekam medik pasien anak di Ruang Theresia RS St. Elisabeth Semarang. Kriteria inklusinya adalah pasien anak di Ruang Theresia RS St. Elisabeth Semarang periode Oktober 2019 - Desember 2019, pasien berusia 6 bulan-14 tahun dan penggunaan antibiotik. Data yang diambil dari rekam medik meliputi umur, jenis kelamin, lama rawat inap. Data penggunaan antibiotik meliputi jenis antibiotik, rute pemberian, dosis dan aturan pakai, serta lama pemberian antibiotik. Pasien yang mendapat antibiotik kombinasi maupun antibiotik topikal di ekslusi.

Data yang diperoleh kemudian dianalisis secara kuantitatif dengan menggunakan metode Anatomical Therapeutic Chemical (ATC) dan Defined Daily Dose (DDD). Kode ATC dan nilai DDD dilihat di situs web ( http://www.whocc.no/atc-ddd-index/ ). Data antibiotik dengan kode J01 dihitung berdasarkan unit DDD/100 patient-days. Proporsi penggunaan antibiotik dihitung berdasarkan unit 
penggunaan tersebut dan antibiotik dengan penggunaan mencapai $90 \%$ dari total penggunaan ditentukan dari proporsi tersebut (DU 90\%)
Kuantitas penggunaan antibiotik dihitung menggunakan metode DDD/ 100 patient-days dengan rumus :

$$
D D D / 100 \text { patient-days: } \frac{\text { jumlah gram antibiotik yang digunakan oleh pasien }}{\text { standar DDD WHO dalam gram }} X \frac{100}{\text { total LOS }}
$$

Keterangan :

1. Jumlah gram antibiotik yang digunakan oleh pasien adalah penggunaan antibiotik yang dinyatakan dalam gram yang dihitung dari perkalian dosis setiap hari dikalikan frekuensi penggunaan dan lama pemberian antibiotik.

2. Standar DDD WHO dalam gram adalah nilai DDD setiap antibiotik yang sudah ditetapkan oleh WHO dan dinyatakan dalam gram.

3. Total Length Of Stay (LOS) adalah total lama rawat inap seluruh pasien

\section{HASIL DAN PEMBAHASAN}

Berdasarkan hasil penelusuran data rekam medik diketahui jumlah pasien rawat inap di ruang Theresia RS St. Elisabeth Semarang periode Oktober - Desember 2019 adalah 385 pasien. Pasien anak yang mendapatkan antibiotik tunggal sebanyak 162 pasien dan selebihnya adalah pasien yang mendapatkan kombinasi antibiotik maupun tidak mendapatkan terapi antibiotik. Total lama rawat inap untuk semua pasien adalah 1117 hari. Karakteristik pasien anak yang mendapatkan antibiotik di ruang Theresia RS St. Elisabeth Semarang dapat dilihat pada Tabel I.

Tabel 1. Karakteristik pasien anak yang mendapatkan antibiotik di ruang Theresia RS St. Elisabeth Semarang periode Oktober-Desember 2019

\begin{tabular}{lcc}
\hline \multicolumn{1}{c}{ Karakteristik } & Jumlah pasien & Persentase (\%) \\
\hline Umur (tahun) & & \\
$<1$ & 23 & 14,20 \\
$1-4$ & 89 & 54,94 \\
$5-9$ & 31 & 19,13 \\
$10-14$ & 19 & 11,73 \\
Jenis kelamin & & \\
$\quad$ Laki-laki & 91 & 56,17 \\
$\quad$ Perempuan & 71 & 43,83 \\
Lama rawat inap (hari) & & \\
$\quad \leq 3$ & 121 & 74,69 \\
$\quad 4-6$ & 38 & 23,46 \\
$\quad \geq 7$ & 3 & 1,85 \\
Jenis Antibiotik & & \\
$\quad$ Seftriakson & 125 & 77,16
\end{tabular}




\begin{tabular}{lcc} 
Sefotaksim & 21 & 12,96 \\
Sefiksim & 8 & 4,94 \\
Seftazidim & 1 & 0,62 \\
Amoksisilin & 3 & 1,85 \\
Ampisilin & 1 & 0,62 \\
Thiamfenikol & 2 & 1,23 \\
Meropenem & 1 & 0,62 \\
\hline
\end{tabular}

Berdasarkan Tabel 1 diketahui bahwa pasien anak di ruang Theresia RS St. Elisabeth Semarang periode Oktober - Desember 2019 yang mendapatkan antibiotik paling banyak adalah pada rentang usia antara $1-4$ tahun $(54,94 \%)$. Usia $1-4$ tahun atau disebut dengan anak balita merupakan tahapan perkembangan anak yang cukup rentan terhadap berbagai serangan penyakit (Kemenkes RI, 2014). Hal ini disebabkan masa balita merupakan masa peralihan antara saat disapih dan mengikuti pola makan orang dewasa, sehingga status gizi anak dapat terganggu akibat anak susah makan. Menurunnya status gizi pada balita dapat meningkatkan kejadian penyakit (Nugroho et al., 2018).

Pasien anak yang mendapatkan antibiotik di ruang Theresia RS St. Elisabeth Semarang periode bulan Oktober - Desember 2019 yang paling banyak berjenis kelamin laki-laki (56,17\%). Anak laki-laki cenderung lebih aktif dibandingkan perempuan, sehingga anak laki-laki lebih sering terpapar agen infeksius yang ada di lingkungan dan lebih mudah terserang penyakit (Ishii dkk, 2015). Penelitian di RSUD Panembahan Senopati Bantul Yogyakarta (Dewi, 2015) dan RSD dr. Soebandi Jember (Fatimatuzzahrah, 2017) juga memberikan hasil yang serupa dimana pasien anak laki-laki jumlahnya lebih banyak.

Lama rawat inap sebagian besar pasien $(74,69 \%)$ adalah $\leq 3$ hari dan ratarata lama rawat inap sebesar 3,02 hari. Jenis antibiotik yang paling banyak digunakan adalah seftriakson $(77,16 \%)$. Seftriakson banyak digunakan sebagai terapi empiris karena merupakan antibiotik spektrum luas yang aktif terhadap bakteri gram positif dan negatif, serta bakteri anaerob (Rachmawati et al., 2020). Seftriakson memiliki harga yang relatif murah serta toksisitas yang relatif lebih kecil untuk pasien anak dibandingkan dengan jenis antibiotik lain (Ardyanti, 2018).

Tabel 2. Nilai DDD/100 patients-days antibiotik yang digunakan di Ruang Theresia RS St. Elisabeth Semarang periode Oktober - Desember 2019

\begin{tabular}{cccccc}
\hline No & Kode ATC & $\begin{array}{c}\text { Jenis } \\
\text { Antibiotik }\end{array}$ & $\begin{array}{c}\text { Rute } \\
\text { Pemberian }\end{array}$ & $\begin{array}{c}\text { DDD Standar } \\
\text { WHO (gram) }\end{array}$ & $\begin{array}{c}\text { DDD/ 100 } \\
\text { Patient-days }\end{array}$ \\
\hline 1. & J01DD04 & Seftriakson & Parenteral & 2 & 15,10 \\
2. & J01DD01 & Sefotaksim & Parenteral & 4 & 1,49 \\
30 & & & & https://doi.org/10.33759/jrki.v3i1.110
\end{tabular}




\begin{tabular}{llllcc} 
3. & J01DD08 & Sefiksim & Oral & 0,4 & 0,69 \\
4. & J01DD02 & Seftazidim & Parenteral & 4 & 0,02 \\
5. & J01CA04 & Amoksisilin & Oral & 1,5 & 0,54 \\
6. & J01CA01 & Ampisilin & Parenteral & 1,5 & 0,10 \\
7. & J01BA02 & Thiamfenikol & Oral & 6 & 0,09 \\
8. & J01DH02 & Meropenem & Parenteral & 3 & 0,14 \\
\hline & & & Jumlah & 18,17 \\
\hline
\end{tabular}

ATC : Anatomical Therapeutic Chemical DDD : Defined Daily Dose

Berdasarkan Tabel 2 diketahui bahwa terdapat 8 jenis antibiotik yang digunakan pasien anak di ruang Theresia Rumah Sakit St. Elisabeth Semarang selama periode Oktober Desember 2019, dengan total nilai DDD/100 patient-days sebesar 18,17 . Nilai DDD tersebut lebih kecil dibandingkan dengan nilai $D D D / 100$ patient-days di RSUD Ngudi Waluyo Wlingi Blitar yaitu sebesar 47,30 (Norcahyanti, 2018) maupun nilai DDD/100 patient-days di RSUD Dr. $\mathrm{H}$. Slamet Martodirdjo Pamekasan yaitu sebesar 76,03 (Ridwan dkk, 2019). Nilai DDD akan linier dengan tingginya penggunaan antibiotik. Semakin kecil kuantitas antibiotik yang digunakan menunjukkan bahwa dokter lebih selektif dalam peresepan antibiotik sehingga lebih mendekati prinsip penggunaan antibiotik yang rasional (Mahmudah, 2016) \& (Pratama, 2019).

Antibiotik dengan nilai DDD/100 patient-days terbesar adalah seftriakson yaitu sebesar 15,10. Nilai ini lebih rendah bila dibandingkan dengan hasil penelitian yang dilakukan di RSUD Dr. H. Slamet Martodirdjo Pamekasan yaitu sebesar 37,56 (Ridwan dkk, 2019). Penelitian yang dilakukan pada tahun 2017 di RSUA Surabaya selama periode November 2016-April 2017 menunjukkan nilai DDD/100 patient-days terbesar adalah seftriakson sebesar 42,49 (Andila dkk, 2017). Hal ini menunjukkan bahwa penggunaan seftriakson di RS St. Elisabeth Semarang lebih selektif sehingga dapat menekan terjadinya resistensi.

Tabel 3. Pola konsumsi antibiotik di Ruang Theresia

RS St. Elisabeth Semarang periode Oktober - Desember 2019

\begin{tabular}{lclccc}
\hline No & Kode ATC & $\begin{array}{c}\text { Jenis } \\
\text { Antibiotik }\end{array}$ & $\begin{array}{c}\text { DDD/ 100 } \\
\text { Patient-days }\end{array}$ & $\begin{array}{c}\text { Persentase } \\
(\%)\end{array}$ & Segmen \\
\hline 1. & J01DD04 & Seftriakson & 15,10 & 83,10 & \\
2. & J01DD01 & Sefotaksim & 1,49 & 8,20 & $90 \%$ \\
3. & J01DD08 & Sefiksim & 0,69 & 3,80 & \\
4. & J01CA04 & Amoksisilin & 0,54 & 2,97 & \\
5. & J01DH02 & Meropenem & 0,14 & 0,77 & \\
6. & J01CA01 & Ampisilin & 0,10 & 0,55 & \\
7. & J01BA02 & Thiamfenikol & 0,09 & 0,50 & $10 \%$ \\
8. & J01DD02 & Seftazidim & 0,02 & 0,11 & 100 \\
\hline
\end{tabular}


Berdasarkan Tabel 3 diketahui bahwa pola konsumsi antibiotik yang masuk ke dalam segmen DU 90\% adalah seftriakson dan sefotaksim. Sedangkan sisanya yaitu sefiksim, amoksisilin, meropenem, ampisilin, thiamfenikol dan seftazdim masuk dalam segmen DU 10\%. Hanya ada 2 jenis antibiotik yang termasuk dalam segmen DU90\%. Semakin sedikit variasi antibiotik yang termasuk dalam segmen DU90\% maka risiko terjadinya resistensi semakin kecil (Mahmudah,

$$
\text { 2016) \& (Pratama, 2019). }
$$

Namun demikian, tetap perlu dilakukan pengendalian penggunaan antibiotik terutama terhadap antibiotika yang masuk kedalam segmen DU $90 \%$. Pengendalian penggunaan antibiotik bertujuan untuk mengendalikan resistensi (Pradipta, 2015). Perlu dilakukan penelitian lanjutan tentang analisis penggunaan antibiotik secara kualitatif dengan metode gyssen, serta dilakukan intervensi yang tepat untuk meningkatkan rasionalitas penggunaan antibiotika serta untuk menekan angka resistensi antibiotik.

\section{SIMPULAN}

Kesimpulan dari penelitian ini adalah :

1. Nilai total Defined Daily Dose (DDD)/100 patient-days di Ruang Theresia RS St. Elisabeth Semarang periode Oktober Desember 2019 adalah 18,17 dengan total lama rawat inap 1117 hari.
2. Antibiotik dengan nilai DDD/100 patient-days paling tinggi adalah seftriakson yaitu 15,10. Sedangkan antibiotika yang masuk ke dalam segmen DU 90\% yaitu seftriakson dan sefotaksim, sehingga harus dipantau penggunaannya karena meningkatkan risiko resistensi.

\section{UCAPAN TERIMAKASIH}

Pada kesempatan ini, peneliti ingin mengucapkan terima kasih kepada berbagai pihak yang telah membantu terwujudnya penelitian ini :

1. Direktur Politeknik Katolik Mangunwijaya Semarang

2. Direktur RS St. Elisabeth Semarang

\section{DAFTAR PUSTAKA}

Andila, VRP., Suprapti, B., Nugroho, CW., Shinta, DW. (2017). Analisis Penggunaan Antibiotika Pada Pasien Rawat Inap di KSM Penyakit dalam Menggunakan Defined Daily, [Skripsi], Surabaya, Fakultas Farmasi Universitas Airlangga.

Ardyanti, AT. (2018). Evaluasi Rasionalitas Penggunaan Antibiotik Pada Pasien Anak Diare Akut di Instalasi Rawat Inap RSUD Kardinah Kota Tegal Periode 2016, [Skripsi], Surakarta, Universitas Setia Budi.

Carolina, M. (2014). Evaluasi Penggunaan Antibiotik Dengan Metode DDD (Defined Daily Dose) Pada Pasien Anak di Rawat 
Inap Bangsal INSKA II RSUP Dr. Sardjito Yogyakarta Periode Januari-Juni 2013, [Skripsi], Yogyakarta, Universitas Sanata Dharma.

\section{Dewi, NPRP. (2015). Evaluasi Penggunaan Antibiotika Berdasarkan Metode PPD (Prescribed Daily Dose) dan DDD (Defined Daily Dose) pada Pasien Rawat Inap di Bangsal Anak RSUD Panembahan Senopati Bantul Yogyakarta Periode Januari-Juni 2014, [Skripsi], Yogyakarta, Universitas Sanata Dharma.}

Fatimatuzzahrah. (2017). Evaluasi Penggunaan Antibiotik pada Pasien Anak Rawat Inap di RSD dr. Soebandi Jember dengan Metode ATC/DDD Periode Tahun 2016, Jember, Universitas Jember.

Ishii K., Shibata A., Adachi M., Nonoue K., Oka K. (2015). Gender and grade differences in objectively measured physical activity and sedentary behavior patterns among Japanese children and adolescents: a cross-sectional study. $B M C$ Public Health, 15(1):1254.

Kemenkes RI. (2011a). Permenkes RI No.2406/MENKES/PER/XII/2011 tentang Pedoman Umum Penggunaan Antibiotik, Jakarta, Kementerian Kesehatan Republik Indonesia.

Kemenkes RI. (2011b). Pedoman Pelayanan Kefarmasian Untuk Terapi Antibiotik, Jakarta, Kementerian Kesehatan Republik Indonesia.

Kemenkes RI. (2014). Permenkes RI No.25 Tahun 2014 tentang Upaya Kesehatan Anak, Jakarta,
Kementerian Kesehatan Republik Indonesia.

Mahmudah, Febrina., Sumiwi, SA., Hartini, Sri. (2016). Studi Penggunaan Antibiotik Berdasarkan ATC/DDD dan DU 90\% di Bagian Bedah Digestif di Salah Satu Rumah Sakit di Bandung, Jurnal Farmasi Klinik Indonesia, 5 (4): 293-298.

Nugroho, KPA., Adi, BPS., Angelina, R. (2018). Gambaran Status Gizi Kurang dan Kejadian Penyakit ISPA Pada Balita di Desa Batur, Kecamatan Getasan, Kabupaten Semarang, Jurnal Kesehatan Kusuma Husada, 233-242.

Norcahyanti, I., Rachmawati, S., Imaniar, H. (2018). Evaluasi Penggunaan Antibiotik Pada Pasien Anak Rawat Inap di RSUD Ngudi Waluyo Wlingi Blitar Dengan Metode ATC/DDD, Prosiding Seminar Nasional dan Rakerda IAI Jawa Timur, Universitas Jember.

Pradipta IS., Ronasih E., Kartikawati AD., Hartanto H., Amelia R., Febrina E., Abdulah R. (2015). Three years of antibacterial consumption in Indonesian community health centers: The application of anatomical therapeutic chemical/defined daily doses and drug utilization 90\% method to monitor antibacterial use, Journal of family \& community medicine, 22(2):101.

Pratama, NYI., Suprapti, Budi., Ardiansyah, AO., Shinta, DW. (2019). Analisis Penggunaan Antibiotik pada Pasien Rawat Inap Bedah dengan Menggunakan 
Defined Daily Dose dan Drug Utilization 90\% di Rumah Sakit Universitas Airlangga, Jurnal Farmasi Klinik Indonesia, 8 (4): 256-263.

Rachmawati, S., Masito, D.K., Rachmawati, E. (2020). Evaluasi Penggunaan Antibiotik pada Pasien Anak Rawat Inap di RSD Dr. Soebandi Jember, Jurnal Farmasi Galenika, 6 (2): 212 220.

Ridwan, A., Narulita, Lisa., Widyadi, ED., Suhardjono. (2019). Analisis Penggunaan Antibiotika pada Pasien Penyakit Dalam di RSUD Dr. H. Slamet Martodirdjo
Pamekasan dengan Metode ATC/DDD, $J$ Sains $F$ arm Klin, 6(3), 237-242.

Sarimawar, D., Ning, S. (2014). Pola Penyebab Kematian Kelompok Bayi dan Anak Balita, Hasil Sistem Registrasi Kematian di Indonesia Tahun 2012, Jurnal Ekologi Kesehatan, 13(3): 265 272.

Satari, HI., Firmansyah, A., Theresia. (2011). Qualitative Evaluation of Antibiotic Usage in Pediatric Patients, Paediatrica Indonesiana, 51(6): $303-310$. 